\title{
Primary Health Care by Vhembe women in the Limpopo province of South Africa: Knowledge and Practice
}

\author{
${ }^{1}$ KyeiKA*, ${ }^{1}$ Netshikweta ML, Spio K ${ }^{2}$ \\ ${ }^{1}$ University of Venda, Limpopo Province South Africa \\ ${ }_{2}^{2}$ Jeffersonville, Indiana, United States of America \\ *kyei61@gmail.com
}

\begin{abstract}
Child mortality has increased in South Africa since 1990, despite a national policy of free primary healthcare for pregnant women and children under the age of five years. A significant number of women and children die during childbirth and $40 \%$ of stillbirths happen during labour. Lack of sufficient knowledge about primary health care (PHC) is costing South Africa greatly because many of the deaths of mothers, babies and young children could be avoided. Teenagers conceal pregnancy and that adds to higher risk of death among themselves and their unborn babies. Almost a half of all new-born babies die during the first 24 hours of birth, and $75 \%$ die in their first week of life. This study looks at primary health care by women in Vhembe by identifying knowledge and skills they possess to deal with health care issues. A 3-stage sample survey was conducted covering all the municipalities in the district. About 2660 women aged between 13 and 50 years were interviewed using structured questionnaire. Applying various statistical methods including logistic and regression modelling, this study shows that majority of the respondents know about PHC and that age and education of women are important factors affecting child's health and survival in the Vhembe district. If Limpopo wants to reduce childhood mortality, this study recommends that efforts be made to educate women, especially teenagers about primary health care, immunization, oral rehydration therapy and attendance at clinics for pre-natal medical check-ups during pregnancy.
\end{abstract}

Keywords: Primary health care, pre-natal medical check-ups, concealment of pregnancy, childhood mortality

\section{Introduction}

Children represent the future and ensuring their healthy growth and development ought to be a prime concern of all societies. Children, particularly new-born babies are vulnerable to infectious diseases, many of which can be effectively prevented or treated. Child's health is closely related to maternal health, because nutrition during pregnancy, birth conditions, birth spacing, and health status of the mother, all impact on the health of the child prior to, during and after birth (UNICEF, 2008). Prenatal medical check-up is a key to protecting the health of the unborn child and the mother. Many child related abnormalities and diseases that could affect the health of the unborn baby and the mother could be picked up and treated before it is too late. This care can help keep a baby healthy and prevent problems during and after delivery (http://www.thenews.com.pk/NewsDetai.aspx?ID=13046). This study looks at primary health care by Vhembe women particularly concerning child's health. The main objective is to identify knowledge and skills to deal with some problems and constraints facing Vhembe mothers with regard to child health care. It therefore seeks to address these key research questions: Do Vhembe mothers give their children the full immunization coverage needed; do they know and practice oral rehydration therapy (ORT) when needed; do they consult health care centres for medical check-ups during pregnancy; and do they deliver their babies in clinics or hospitals with professional health workers in attendance?

\section{Literature Review}

Primary Health Care: Many childhood diseases are preventable if the proper immunisation is done for the child. Children who are not immunized are at high risk of becoming infected with many preventable diseases (UNICEF, 2008, 2011). Immunization is one of the greatest medical achievements in human history and has saved millions of lives in the $20^{\text {th }}$ century. When the World Health Organisation (WHO) began its immunization programmes in 1974, less than $5 \%$ of the world's children were immunized. Twenty-six years 
later, it increased to over 75\%. Millions of children's lives have been saved and the burden of vaccine preventable diseases have been considerably reduced (WHO, 2011). While many diseases have disappeared from the public eye, paradoxically the debate about safety of immunization is still very much alive (Department of Health, (DoH), South Africa, 2004). Immunization protects young children from deadly childhood diseases. Some of the diseases that can be prevented by childhood immunization are: Polio, Measles, Mumps B, Rubella, Diphtheria, Pertussis (whooping cough), tetanus and meningitis. These diseases can cause crippling and sometimes death (DoH, 2005). In 2009, estimated global coverage with three doses of diphtheria, tetanus and pertussis vaccine increased to $82 \%$ compared to $74 \%$ in 2000 . More infants with estimation of 107.1 million were vaccinated than ever before in 2009. However, an estimated 23.2 million infants worldwide are still not being reached by routine immunization services. About $70 \%$ of these children live in ten countries and more than half of them live in India and Nigeria, (CDC, 2010). Some children get immunization but do not take the full course. MayleneShung-King refers full immunisation to children having received all the required doses of vaccines given in the first year of life (Shung-King, 2010). Access to prenatal medical care is critical for reducing maternal and infant morbidity and mortality, notwithstanding and unfortunately rural women tend to receive less adequate prenatal care than their urban counterparts because of limited resources in the rural areas. The risk factors for these conditions tend to disproportionately affect women in rural areas, nonetheless the health status of rural mothers and infants can be largely improved by eliminating existing barriers to quality and comprehensive prenatal care. Ultimately, improving the health of rural mothers and infants, from preconception to pregnancy to birth and beyond, advances the health of the next generation (Peck and Alexander, 2012). Female formal education, especially up to the completion of grade ten, has been noted as an important determinant of child survival (Caldwell, 1979; Tekce and Shorter, 1984; Ruzickaet al,. 1989; Kyei, 1999).

Limpopo province: The Limpopo province is located in the northern most part of the country neighbouring Botswana, Mozambique and Zimbabwe. The province covers a land size of $123910 \mathrm{~km}^{2}$; accounting for $10.2 \%$ of South Africa's total land area \{Statistics South Africa, (StatsSA), 2003\}. Majority of the population reside in rural areas in comparison to the national average of $50 \%$. However due to its rural make-up, conditions are substandard compared to the rest of the country with the exception of the Eastern Cape Province (Gyekye and Akinboade, 2001). Limpopo is characterized as a developing economy, portraying positive growth patterns. For instance, it experienced its highest growth of 3.8\% between 1995 and 2001. Furthermore, its gross geographical product was quantified at 63646 million rand signifying a $6 \%$ contribution to national Gross Domestic Product (i.e. the $3^{\text {rd }}$ smallest provincial contribution) (StatsSA, 2003). The most significant contributors to its economy are community, social and personal service, agriculture, forestry and hunting, wholesale and retail trade. The province is endowed with variety of minerals such as gold, and platinum among others; hence mining is one of the mainstay of its economy. However these minerals are exported in their raw state and in return manufactured goods and services are imported.

Population structure of Limpopo: The total population of the Limpopo province, according to the latest census 2011 figures released, is 5404868 representing 10.4\% of South Africa's total population (StatsSA. 2013). More than half of its population is female (i.e. 53\%), with female dominance noticeable in the adult categories. This may be explained by the high migration rates of adult males in search of jobs in other provinces, notably in Gauteng province, and in the old age category due to longer survival of women. A little over $40 \%$ of the total population in the Limpopo province is less than 15 years and $6 \%$ were aged 60 years and above depicting a tendency of high dependency ratio. The total population is mainly African with a share of $97.2 \%$ compared with $0.2 \%, 0.2 \%$ and $2.4 \%$ for Coloured, Indian and White respectively.

Economic Conditions in Limpopo: The 2001 Census recorded that $33.4 \%$ of the population aged 20 years and above had no formal education (i.e. 1 in every 3 people had no literacy skills). Nearly half (49\%) of the economically active people are unemployed and 33\% of the employed were in the informal sector. Poverty prevalence was very high, as 6 in every 10 persons fell below the poverty line in 2002 (StatsSA, 2003). A little over $70 \%$ of the population lived in formal dwellings, $20 \%$ and $7 \%$ lived in traditional and informal dwellings respectively. Majority (i.e. 78\%) of households had access to clean drinking water. Approximately one in every 4 households had no access to the toilet facilities and only $14 \%$ had refuse removal service. Majority (i.e. $60 \%$ ) of households still used wood as their main source of energy for cooking, $25 \%$ and $11 \%$ of household used electricity and paraffin respectively (StatsSA, 2003). 
History of Vhembe district: Vhembe is one of the five districts in the Limpopo province. It was originally settled by the now-expired tribes of the Khoisan People. It was later settled by the Venda people (migrated from what is now Matabeleland South in Zimbabwe), who constitute a majority of the population of Vhembe today. The Dzataruins in Thulamela local municipality once served as the main settlement and capital of the Venda empire which had dominated the area during the 18th century (www:absoluteastronomy.com).Boer settlement of the territory began in the late 18th century and gradually up-surged throughout the 19th century. By the turn of the century, the Soutpansberg was taken by the Boers from the Venda rulers, making it one of the last areas in the future republic of South Africa to come under white rule. During the apartheid era, the Bantustan of Venda (declared independent in 1973) was established in the eastern part of the Vhembe area, and was reintegrated into the country at the end of white minority in 1994.

\section{Methodology}

Materials/Data: The data were obtained through a 3-stage sample survey conducted to cover all the municipalities in the Vhembe district between March and September 2010. The locations that were eventually sampled and studied were Vuwani, 643 households, Malamulele "town" 709 households, Malamulele villages 649 households, Makwarela 283 households and Dzata (Mphephu) 379 households. About 2660 women aged between 13 and 50 years were interviewed. Structured questionnaire was used to capture information from these women in the child-bearing age. The questionnaire used has items on social, economic, demographic and health variables of the respondents such as age, marital status, level of education, employment status, number of years married, number of children born, contraception, pregnancy, ante-natal visits to clinics, immunization, breastfeeding, common illnesses and diseases, child care, oral rehydration therapy and other health-related variables as well as vital statistics questions.

Methods/ Analysis: Initially cross tabulation was done before regression (Logistic Regression analysis and multiple regressions) analyses. Cross tabulations are generally useful to identify the relationship between independent and dependent variables. The relationship is determined by the value of Chi-Square. The Pearson Chi-square was used as a measure of association at $5 \%$ level of significance. It is the most common test for significance of the relationship between categorical data. The fixed at 0.05 shows the level of association from the Chi-square test.

Logistic Regression: After the cross tabulation, logistic regression was also done as stated earlier. Logistic Regression is a type of predictive model that can be used when the target variable is a categorical variable with two categories. A logistic regression model does not involve decision trees and is more akin to nonlinear regression such as fitting a polynomial to a set of data values. The logistic model formula computes the probability of the selected response as a function of the values of the predictor variables (Agresti, 1996) Mathematically, the model equation is given by

$\operatorname{Logit}[\theta(x)]=\log \left[\frac{\theta(x)}{1-\theta(x)}\right]=\alpha+\beta_{1} x_{1}+\beta_{2} x_{2}+\ldots+\beta_{i} x_{i}$

If a predictor variable is categorical variable with two values, then one of the values is assigned the value 1 and the other is assigned the value 0 (www.dtreg.com/logistic.htm). Two different dependent variables were used in the study; these were pre-natal medical check-up and knowledge of oral rehydration. The independent variables used were the same for both models. The variables were education, age group and employment status.

\section{Results}

Table 1 gives the frequency of some socio-demographic variables. About $48 \%$ of the 2299 women interviewed were more than 36 years old while an insignificant 3.1\%were teenagers. [Teenagers were undersampled because the survey covered women with children.] Over 55\% were unemployed (not working), $30 \%$ were working and $14 \%$ were working for family or for self. The distribution of the level of education is as follows: women completed grade 12 and other qualifications accounted for (37.1\%), those completed grade 8 to 11 formed (28.9\%), those who had tertiary qualifications (22.4\%), those who had primary 
education $(11.4 \%)$ and $0.1 \%$ of the women did not go to school. This makes the total of 1493 women who responded to the question on educational level.

Table 1: Frequency table for some socio-demographic indicators

\begin{tabular}{lll}
\hline Variables & Frequency & Percentage \\
\hline Age & 71 & \\
$15-19$ & 425 & 3.1 \\
$20-25$ & 694 & 18.5 \\
$26-35$ & 1109 & 30.2 \\
$36+$ & 2299 & 48.2 \\
Total & & 100 \\
Employment Status & 1273 & \\
Not working & 322 & 55.7 \\
Work for self or family & 691 & 14.1 \\
Work for somebody else & 2286 & 30.2 \\
Total & & 100 \\
Educational level & 182 & \\
Grade R to 7 & 369 & 12.2 \\
Grade 8 to11 & 550 & 24.7 \\
Grade12 to 12+ & 390 & 36.8 \\
Tertiary & 2 & 26.4 \\
No schooling & 1493 & 0.1 \\
Total & & 100 \\
\hline
\end{tabular}

Source: Survey data 2010

Table 2: Frequency of other health variables/indicators

\begin{tabular}{lll}
\hline Variables & Frequency & Percentage \\
\hline $1-3$ months & 209 & 58.4 \\
$4-6$ months & 96 & 26.8 \\
$7-9$ months & 53 & 14.8 \\
Total & 358 & 100 \\
Place of birth of their last child (less than 5 years) & & \\
Hospital & 261 & 73.5 \\
Clinic & 90 & 25.4 \\
Home & 2 & 0.6 \\
Other & 2 & 0.6 \\
Total & 355 & 100 \\
Birth mass(kg) of their last born & & \\
$<2.5$ & 23 & 18.7 \\
2.5 to 4 & 99 & 80.5 \\
$>4$ & 1 & 0.8 \\
Total & 123 & 100 \\
\hline
\end{tabular}

Source: Survey data 2010

Table 2 gives information about women whose babies were less than three years old and who responded to questions about primary health care. Out of 355 women who responded to the question concerning pre-natal consultations for medical check-ups, $58.4 \%$ of the women stated that they started their pre-natal medical check-ups when they were 1 to 3 months pregnant, 26.8\% of the women started when they were 4 to 6 months pregnant and $14.8 \%$ started when they were 7 to 9 months pregnant. For the place of birth of their 
last child whose age was less than 5 years, $73.5 \%$ of the women said that their last child was born in hospital, $25.4 \%$ said that their babies were born at the clinic and only $0.6 \%$ said their babies were born at home. Less than one per cent $(0.6 \%)$ of the women said they gave birth somewhere else. Concerning the weights of babies at birth, $18.7 \%$ of the women gave birth to under-weight babies ( 0 to $2.4 \mathrm{~kg}$ ), while the majority of them $(80.5 \%)$ gave birth to children with normal birth weight (2.5 to $4 \mathrm{~kg})$ and only 1 woman $(0.8 \%)$ gave birth to babies whose weights were more than normal ( $>4 \mathrm{~kg})$.

Table 3: Common childhood diseases and their treatments

\begin{tabular}{|c|c|c|}
\hline Variables & Frequency & Percentage \\
\hline \multicolumn{3}{|c|}{ Has your child had diarrhoea in the last two weeks? } \\
\hline Yes & 62 & 18.3 \\
\hline No & 277 & 81.7 \\
\hline Total & 338 & 100 \\
\hline \multicolumn{3}{|c|}{ Was the child given ORS? } \\
\hline Yes & 34 & 54.8 \\
\hline No & 28 & 45.2 \\
\hline Total & 62 & 100 \\
\hline \multicolumn{3}{|c|}{ Was the child taken to any health care centre? } \\
\hline Yes & 36 & 58.1 \\
\hline No & 26 & 41.9 \\
\hline Total & 62 & 100 \\
\hline \multicolumn{3}{|c|}{ Has your child sufferd from severe cough or difficult breathing in the last four weeks? } \\
\hline Yes & 93 & 27.3 \\
\hline No & 248 & 72.7 \\
\hline Total & 338 & 100 \\
\hline \multicolumn{3}{|c|}{ Was the child taken to any health care centre? } \\
\hline Yes & 69 & 74.2 \\
\hline No & 24 & 25.8 \\
\hline Total & 93 & 100 \\
\hline \multicolumn{3}{|c|}{ Has your child had Measles in the last 3 months? } \\
\hline Yes & 9 & 2.6 \\
\hline No & 340 & 97.4 \\
\hline \multicolumn{3}{|c|}{ Was the child taken to any health carecentre? } \\
\hline Yes & 5 & 55.5 \\
\hline No & 4 & 44.5 \\
\hline Total & 9 & 100 \\
\hline
\end{tabular}

Source: Survey data 2010

Table 3 gives some common childhood diseases and their treatments. About $18 \%$ of the 340 women interviewed said that their little children had had diarrhoea two weeks before the survey and about $27.3 \%$ of the women said their children had suffered severe cough four weeks prior to the interview. Out of those women who said their children had suffered severe cough, $74.2 \%$ of the women took their children to the health care centre for treatment while $25.8 \%$ did not take their children to any health care centre. For 
measles, only $2.6 \%$ said that their children suffered from it three months prior to the interview while $97.4 \%$ of the women responded negatively, saying that their children did not have measles. For women whose children had had measles, about $55.5 \%$ of them said that they took their children to health care centre for treatment, but $44.5 \%$ did not take their children to any health care centre for treatment.

Chi- square tests: The chi-square test shows that pre-natal medical check-up has a strong relationship with age such that the older women consult earlier during pregnancy than the young ones. The younger women, especially the teenagers hide the pregnancy until late, 6 months or more before they begin to consult. The test similarly shows that the more educated women start consulting early (1 to 3 months pregnancy) while the less educated, women with primary school education or women with no schooling start, consultations late. Concerning employment, the test could not confirm any relationship between employed, non-employed and the timing of consultation for medical check-ups (Table 4; Fig. 1 and Fig. 2).

Table 4: The relationship between pre-natal medical check-ups and independent variables - age, educational level and employment status

\begin{tabular}{llll}
\hline \multicolumn{1}{l}{ Variables } & \multicolumn{1}{l}{ Starting time for prenatal visits to health care centre } \\
\hline Age (years) & 1 to 3 & 4 to 6 & 7 to 9 \\
$15-19$ & 28.0 & 48.0 & 24.0 \\
$20-25$ & 43.0 & 31.0 & 26.0 \\
$26-35$ & 62.8 & 23.1 & 14.0 \\
$36+$ & 69.9 & 24.7 & 5.5 \\
$\chi^{2}=27.375, \quad p$-value $=0.000$ & & \\
Educational Level & 1 to 3 & 4 to 6 & 7 to 9 \\
Grade R-Grade7 & 36.4 & 54.5 & 9.1 \\
Grade 8-Grade 11 & 37.5 & 29.2 & 33.3 \\
Grade 12-12+ & 62.3 & 27.5 & 10.2 \\
Tertiary & 77.5 & 20.0 & 2.5 \\
$\chi^{2}=49.610$, & $p$ - value $=0.000$ & & \\
Employment Status & 1 to 3 & 4 to 6 & 7 to 9 \\
Working For somebody else & 62.7 & 22.7 & 14.5 \\
Working for self or family & 59.0 & 26.2 & 14.8 \\
Not working & 55.7 & 30.1 & 14.2 \\
$\chi^{2}=5.769$, & $p$ - value $=0.763$ & & \\
\hline
\end{tabular}

Source: Survey data 2010

Figure 1: Age group and staring time for prenatal visits

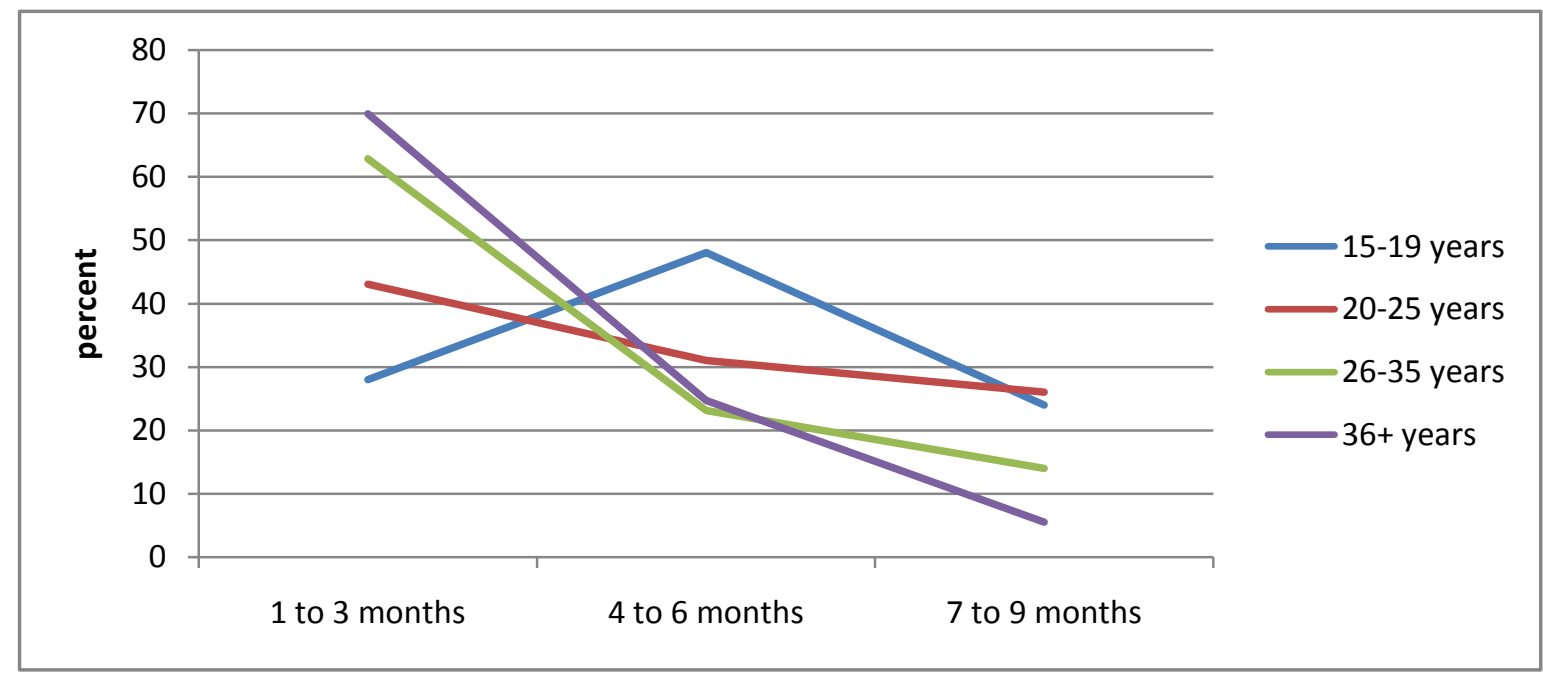

Source: Survey data 2010 
Figure 2: Educational level and starting time for prenatal consultation visits

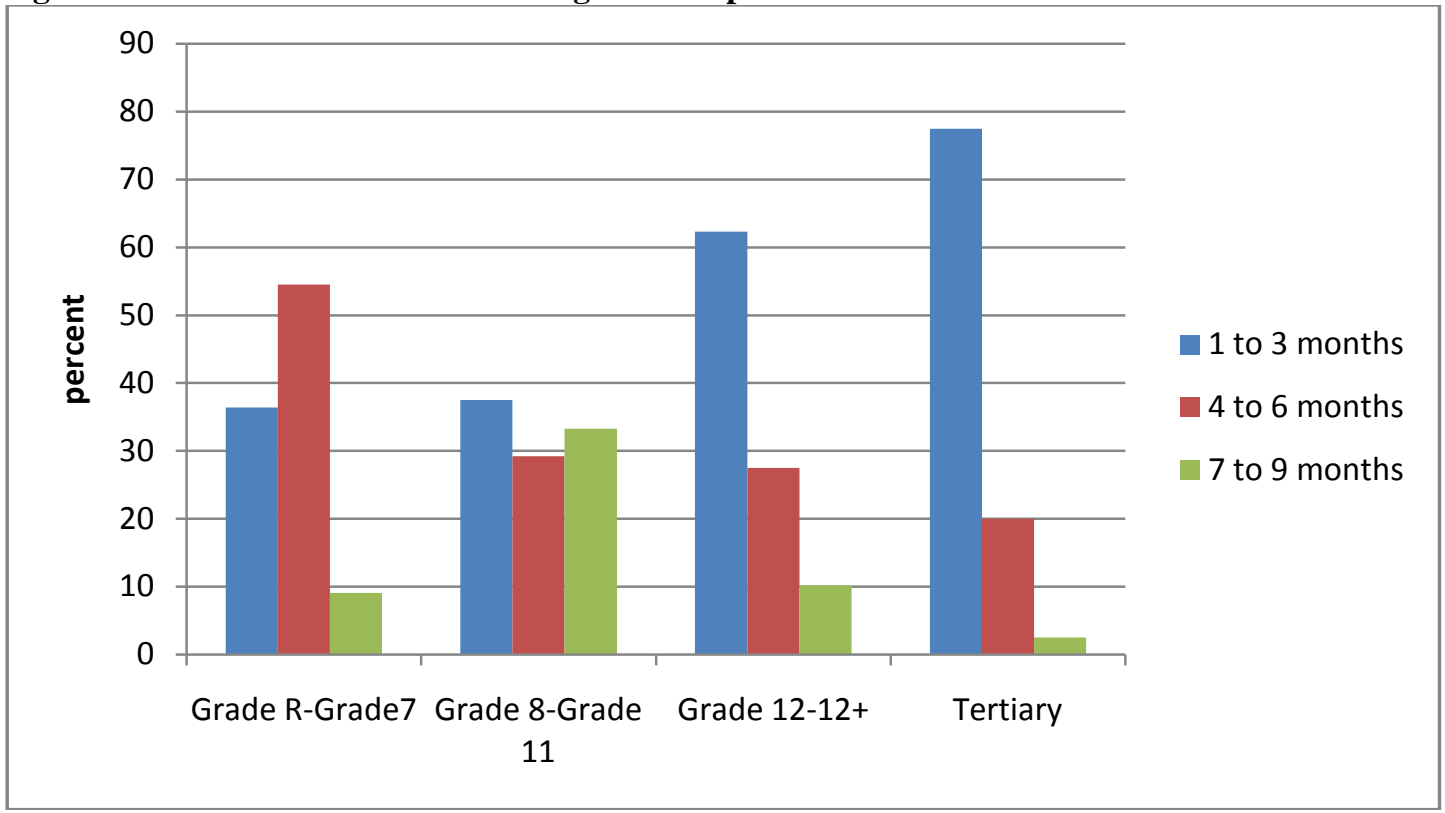

Source: Survey data 2010

Knowledge about ORT and women's age: The chi-square test could not prove any relationship between knowledge about oral rehydration therapy (ORT) and age. Rather the test showed a strong relationship between knowledge about ORT and education, as well as knowledge about ORT and employment. The test confirmed what was expected, that the more educated women are more knowledgeable about ORT than the less educated women. Surprisingly, the test also showed that knowledge about ORT is strongly related to employment such that the unemployed have better knowledge about ORT than those employed (see Table 5, and Fig. 3). Why the unemployed have better knowledge about ORT than the employed is a matter of further research.

Table 5: Relationship between knowledge about ORS for the treatment of the child with diarrhoea and independent variables

\begin{tabular}{lll}
\hline Variables & Do you know how to mix ORS? & \\
\hline Age (years) & Aware & Not aware \\
$15-19$ & 85.5 & 14.5 \\
$20-25$ & 88.1 & 11.9 \\
$26-35$ & 87.0 & 13.0 \\
$36+$ & 85.7 & 14.3 \\
$\chi^{2}=0.187, p-$ value $=0.845$ & & \\
Educational level & Aware & Not aware \\
Grade R to7 & 88.1 & 11.9 \\
Grade 8 to11 & 86.6 & 13.4 \\
Grade 12 \&12+ & 82.0 & 18.0 \\
Tertiary & 91.6 & 8.4 \\
$\chi^{2}=10.557, p-$ value $=0.032$ & \\
Employment status & & Aware \\
Working For somebody else & 75.4 & 24.6 \\
Working for self or family & 84.6 & 15.4 \\
Not working & 87.8 & 12.2 \\
$\chi^{2}=14.036, p-$ value $=0.001$ & \\
\hline
\end{tabular}

Source: Survey data 2010 
Figure 3: Educational level and knowledge about oral rehydration therapy

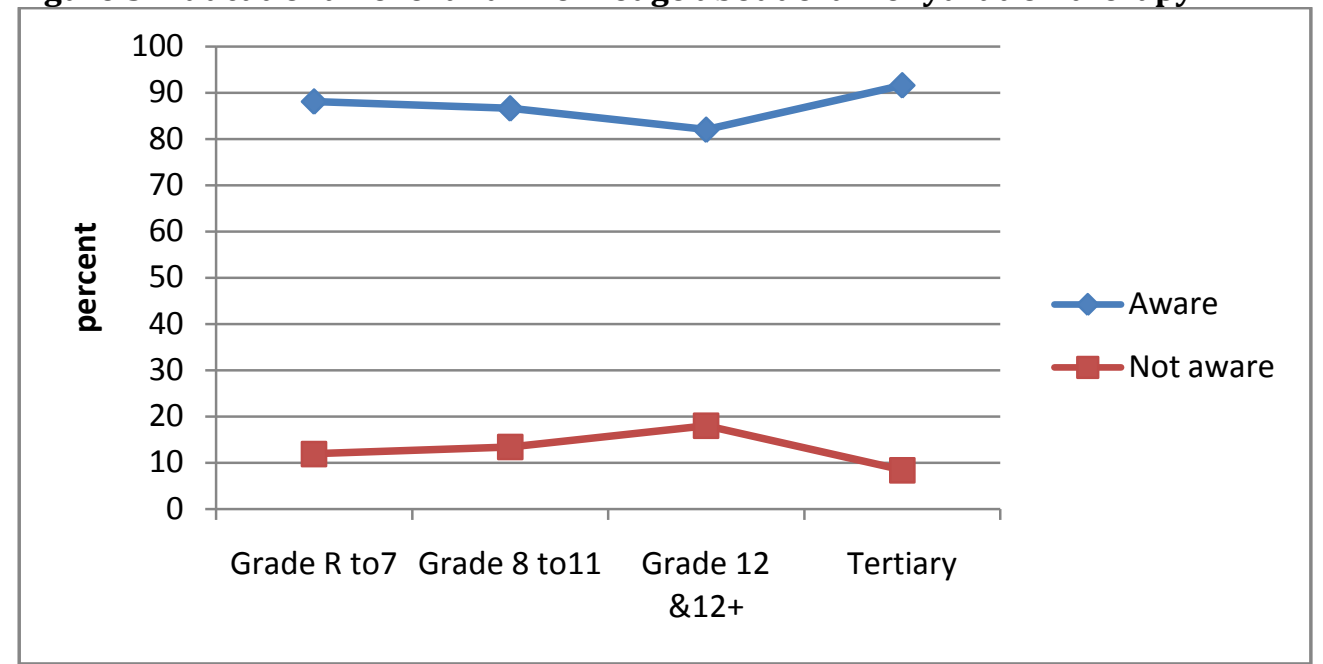

Source: Survey data 2010

Logistic regression: After the cross tabulation analysis, the data were transformed to enable Logistic regression analysis also to be done as a confirmation. The Chi-Square test found out the following; that:

- there is a relationship between pre-natal medical check-ups and age; and

- there is a relationship between pre-natal medical check-ups and the level of education; on one hand; and

- there is a relationship between knowledge about oral rehydration therapy (ORT)and the level of education; and

- there is a relationship between knowledge about ORT and employment status; on the order hand.

Logistic regression analysis was done to ascertain these findings. Table 6 confirms, from the logistic regression analysis, that indeed the relationship between prenatal medical check-ups and age on one hand and education on the other hand is very strong. Equally, Table 7 confirms that the relationship between ORT and the level of education on one hand, and employment status on the other is very strong.

Table 6: Variables in the Equation : starting time for prenatal medical check - ups.

\begin{tabular}{lllllll}
\hline & B & S.E. & Wald & Df & Sig. & Exp(B) \\
\hline Age Group & & & 17.904 & 3 & .000 & \\
Age group (1) & 1.664 & .578 & 8.302 & 1 & .004 & 5.282 \\
Age group (2) & 1.350 & .385 & 12.278 & 1 & .000 & 3.859 \\
Age group (3) & .347 & .367 & .895 & 1 & .344 & 1.415 \\
Educational level & & & 6.831 & 2 & .033 & \\
Educational level (1) & .870 & .959 & .824 & 1 & .364 & 2.387 \\
Educational level (2) & .836 & .330 & 6.395 & 1 & .011 & 2.306 \\
Working & & & 2.497 & 2 & .287 & \\
Working (1) & .637 & .463 & 1.891 & 1 & .169 & 1.890 \\
Working (2) & .367 & .324 & 1.286 & 1 & .257 & 1.443 \\
Constant & -1.117 & .353 & 9.990 & 1 & .002 & .327 \\
\hline
\end{tabular}


Table 7: Variables in the equation: knowledge about oral rehydration therapy

\begin{tabular}{lllllll}
\hline & B & S.E. & Wald & Df & Sig & Exp(B) \\
\hline Educational level & & & 6.269 & 2 & .044 & \\
Educational level (1) & .702 & .552 & 1.617 & 1 & .204 & 2.018 \\
Educational level (2) & .602 & .262 & 5.282 & 1 & .022 & 1.825 \\
Age group & & & 1.251 & 3 & .741 & \\
Age group (1) & -.227 & .438 & .270 & 1 & .603 & .797 \\
Age group (2) & .009 & .299 & .001 & 1 & .976 & 1.009 \\
Age group & .191 & .283 & .457 & 1 & .499 & 1.211 \\
Working & & & 11.840 & 2 & .003 & .913 \\
Working(1) & -.091 & .374 & .059 & 1 & .807 & .430 \\
Working (2) & -.844 & .249 & 11.467 & 1 & .001 & .430 \\
Constant & 1.774 & .260 & 46.513 & 1 & .000 & 5.896 \\
\hline
\end{tabular}

Source: Survey data 2010

Log odd (Pre-natal Medical Check-ups) $=\beta_{0}-\beta_{1}$ (age) $-\beta_{2}$ (educational level).........(2)

That is

Log odd (Pre-natal Medical Check-ups $)=-1.117+1.664$ (age) $+0.836($ educational level $)$.

implying

Odd ratio (Pre-natal Medical Check-ups) $=0.327+5.282$ age +2.306 educational level; and for ORT;

Log odd ( Knowledge about ORT) $=1.774+0.602$ (educational level) -0.844 (Employment status)

This implies that

Odd ratio (Knowledge about ORT) $=5.896+1.825$ educational level +0.430 employment status.

Discussion: While the older women consult early when they are pregnant, the younger women, especially the teenagers, start their prenatal consultations late. These ignorant teenagers feel ashamed or are shy when they get pregnant and therefore try to hide the pregnancy. Report by Child trends database (2010) shows that, in the United States of America about $15.6 \%$ of the girls under the age of 15 years and $6.4 \%$ of teenagers between 15 to 19 years who gave births in 2006 received late or did not go for prenatal medical check-ups when they were pregnant. This proportion drops steadily as women get older, reaching $2.4 \%$ for women in their early thirties. This report supports the findings in that study. The older women consult early because they had already given birth or fallen pregnant before; therefore they know the implications and consequences of not going for prenatal medical consultations early. Besides, older women who are over 35 years are at high risk of developing high blood pressure and diabetes when pregnant so consulting earlier enables them to detect any unforeseen problem to quickly address it. Mothers who receive late or no prenatal medical check-ups are more likely to have babies with health problems. According to Child trends database (2010), they are three times more likely to give birth to a low weight baby, and their babies are five times more likely to die. The timing of first prenatal medical check-ups visit is strongly associated with educational level. In the United States, in 1988, 92\% of mothers with at least college education started their prenatal medical check-ups early compared to $53 \%$ of mothers who had less than a high school education. The probability that a pregnant woman will start her prenatal medical check-ups late or does not go for prenatal medical check-ups decreases as her educational level increases (Kiely \& Michael 1994).

A study which covered 65,519 infants from birth cohort in Philadelphia's immunization registry, showed that 11090 infants' mothers constituting $12.6 \%$ were late starters of prenatal medical consultations. Infants, whose mothers were younger, received less than five prenatal medical check-ups, had less than a high school education, had more than two children, and who smoked cigarettes during pregnancy were women who were unquestionably more often the late starters. Young mothers with higher birth order, and fewer prenatal consultations at public health clinics were the strongest predictors of being a late starter for taking their children for immunization (Feemster et al., 2009). The Chi-square statistics from Table 5 show that high level of education was associated with early prenatal medical check-ups ( 1 to 3 months pregnancy) ( $p$-value = 0.000). Women with high education start their prenatal visits earlier than women with lower level of education because women who are well educated are knowledgeable and understand the importance of going 
for prenatal consultations early. Incidentally our data on immunization could not permit us to find any relationship with the independent variables because the questions on immunization refer to dates when mothers took their children for immunization. There were no questions on the number of times they took their children for immunization, neither were there questions on whether their children completed or not their full immunization schedules. The logistic regression analysis shows that the age of the women is associated with the starting time for prenatal medical check-ups during pregnancy ( $p$-value $=0.000)$.Women who were young 15 years thereabout started their prenatal medical check-upslater than those who were more matured, aged 30 years or more. The probability that a pregnant woman starts prenatal medical checkups early increases with increasing level of educational. The results above again confirm the results from the chi-square tests. These results indicate that the explanatory variables for the starting time for prenatal medical check-ups are the level of education and age, at 5\% significance level.

Recall the model:

Log odd $=\beta_{0}-\beta_{1}$ (age) $-\beta_{2}$ (educational level)

That is,

Log odd (Pre-natal Medical Check-ups $)=-1.117+1.664$ age +0.836 educational level

This implies that

Odd ratio (Pre-natal Medical Check-ups) $=0.327+5.282$ age +2.306 educational level

Multiple Regression - Ordinary Least Squares: Since the categorical data (dependent variables) were coded as 0 and 1, multiple regressions (OLS) and General Linear Modelling (ANOVA) were also done as a further confirmation of the results from chi-square and logistic regression (Menard, 1995; Lemeshow, 2004). The results from the general linear model and regressions analyses seen in Table 8 and Table 9 confirm that starting time for prenatal medical check-ups has a very strong negative relationship with age of the women $(p$-value $=0.000)$ and educational level $(p$-value $=0.017)$, that the older women and the more educated start their check-ups earlier than the younger and the less educated. In this case, there is also some relationship of the timing for medical check-up with employment though the relationship is weak.

Table 8: ANOVA of starting time for prenatal consultation

\begin{tabular}{llllll}
\hline & Sum of square & DF & Mean square & F & Sig. \\
\hline Regression & 5.875 & 3 & 1.958 & 8.524 & $\mathbf{0 0 0}$ \\
Residual & 55.374 & 241 & .230 & & \\
Total & 61.249 & 244 & & & \\
\hline
\end{tabular}

a. Predictors: (Constant), Employment status, Educational level, Age Group

b. Dependent Variable: Prenatal medical check-ups

Source: Survey data 2010

Table 9: Coefficients of starting time for prenatal consultation

\begin{tabular}{|c|c|c|c|c|c|}
\hline \multirow[t]{2}{*}{ Model } & \multicolumn{2}{|c|}{$\begin{array}{l}\text { Unstandardized } \\
\text { Coefficients }\end{array}$} & \multirow{2}{*}{$\begin{array}{l}\begin{array}{l}\text { Standardized } \\
\text { coefficients }\end{array} \\
\text { Beta }\end{array}$} & \multirow{2}{*}{$\mathbf{T}$} & \multirow{2}{*}{ Sig } \\
\hline & B & Std. Error & & & \\
\hline (Constant) & 1.277 & .186 & & 6.852 & .000 \\
\hline Age group & -.149 & .035 & -.275 & -4.313 & .000 \\
\hline Educational level & -150 & .062 & -.149 & -2.413 & .017 \\
\hline Employment status & .085 & .066 & .083 & 1.290 & .198 \\
\hline
\end{tabular}

Dependent Variable: Prenatal medical check-ups

Source: Survey data 2010

The model is as follows: 


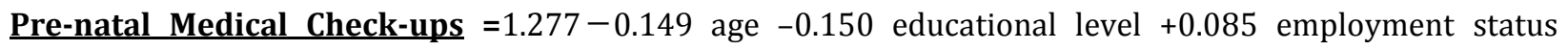
(9)

(Unstandardized)

Pre-natal Medical Check-ups $=-0.275$ age -0.149 educational level +0.066 employment status ...(10)

$\underline{\text { ORT }}$

(Standardized)

The results from Table 10and Table 11 also confirm that educational level and employment status have an impact on the knowledge about oral rehydration therapy. The model from this analysis is as follows:

Knowledge about ORT $=0.989+0.005$ age -0.047 educational level -0.075 employment...

(Unstandardized)

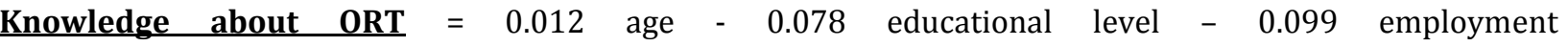
status.

(Standardized)

Table 10: ANOVA of ORT knowledge

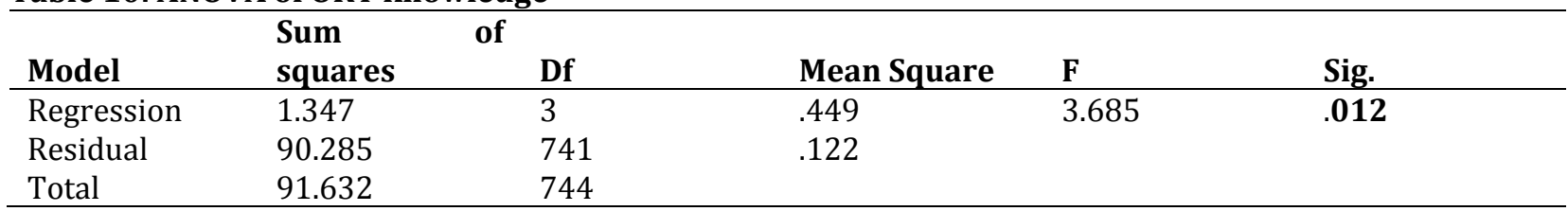

Source: Survey data 2010

Table 11: Coefficients of ORT knowledge

\begin{tabular}{|c|c|c|c|c|c|}
\hline \multirow{3}{*}{ Model } & \multicolumn{2}{|c|}{$\begin{array}{l}\text { Unstandardized } \\
\text { Coefficients }\end{array}$} & \multirow{2}{*}{$\begin{array}{l}\text { Standardized } \\
\text { Beta }\end{array}$} & \multirow[b]{2}{*}{$\mathbf{T}$} & \multirow[b]{2}{*}{ Sig. } \\
\hline & B & St. Error & & & \\
\hline & .989 & .074 & & 13.347 & .000 \\
\hline Age group & .005 & .015 & .012 & .329 & .743 \\
\hline Educational level & .047 & .022 & .078 & 2.127 & .034 \\
\hline Employment status & -.075 & .028 & -.099 & -2.647 & .008 \\
\hline
\end{tabular}

.a. Dependent Variable: ORS_Knowledge

Source: Survey data 2010

Knowledge about ORT is negatively related to employment status of the woman. Unemployed women are more knowledgeable about ORT than those who are working for somebody else or for family or for themselves. Similarly, the regression analyses (Multiple regression and logistic regression) also confirm that educational level and employment status have strong relationship with knowledge about Oral rehydration Therapy. Employment status was not expected to have any relationship with ORT but our analysis has proved otherwise. It has been confirmed in this study that women's education after nine-successful-years of schooling (after grade nine) is a necessary and essential factor to promote a decline in childhood mortality. Women who are highly educated have more knowledge about ORT than those who are less educated. These results are supported by the study done by Anidi et al. (2002).

\section{Conclusion}

The study has revealed that in Vhembe, younger women, especially teenagers, start prenatal medical checkups late and this has negative implications for themselves and their unborn babies because such practices contribute to higher childhood and maternal mortality. Some children are stillborn because of such practices, where careless women do not go for prenatal medical check-ups during pregnancy or do so late. The 
proportion of women aged 36+ years who started their prenatal consultations early is more than twice that of women aged 15 to 19 years who started theirs at the same period of pregnancy. The results in this study show that majority of the women seem to know and understand the use of ORS. Table 4 shows that $92.2 \%$ of the respondents knew about ORT and have made use of the solution when their children were ill with diarrhoea. Women's knowledge about ORT was also found to have a relationship with the level of education $(p$-value $=0.032)$ and employment status $(p$-value $=0.001)$. For the place of birth of their last child whose age was less than 5 years, $73.5 \%$ of the women said that their last child was born in hospital; about $25.4 \%$ said that their babies were born at the clinic and only $0.6 \%$ said their babies were born at home. Less than one per cent $(0.6 \%)$ of the women said they gave birth somewhere else. As far as the place of delivery is concerned, women in Vhembe do very well because almost everybody gave birth in a health centre with a professional medical/health attendant present. Concerning the weights of babies at birth, $18.7 \%$ of the women gave birth to under-weight babies ( 0 to $2.4 \mathrm{~kg}$ ), while the majority of them (80.5\%) gave birth to children with normal birth weight ( 2.5 to $4 \mathrm{~kg}$ ) and only $1(0.8 \%)$ woman gave birth to babies whose weights were more than normal ( $>4 \mathrm{~kg}$ ). The need to encourage female higher education cannot be over emphasized. This study recommends that women pursue higher education because research shows that the level of education has a positive relationship with healthcare practices, including prenatal medical check-ups and knowledge about ORT.

\section{References}

Agresti, A. (1996). An Introduction to Categorical Data Analysis. Second edition, John Wiley and Sons, Inc. New York.

Anidi, I., Bazargan, M. \& James, F. W. (2002). Knowledge and Management of diarrhea among underserved minority parents/caregivers. Ambul Pediatr, 2, 201 - 206.

Bupa's Health Information Team. (2010). Measles, Mumps and Rubellavaccine.www.bupa.co.uk/individuals/health-information/.../m/mmr-vaccine(Retrieved, 14 December 2011).

Caldwell, J. C. (1979). Education as a factor in mortality decline: An examination of Nigerian data. Population Studies, 33(4), 395-413.

CDC. (2010). Global routine vaccination coverage 2009.Morbidity and Mortality weekly report (MMWR) October 29, 2010/59(42); 1367-1371.)

Child trends databank. (2010). Late or no prenatal care.www.childtrendsdatabank.org/?q=node/243.(Retrieved, 23 June 2011).

Department of Health. (2004). Immunization is safe EPI (SA) Fact sheet. http://www. westerncape.gov.za/text/2005/7/facts_about_immunisation.pdf.(Retrieved, 6 May 2011).

Department of Health. (2005). Immunization is safe EPI (SA) Fact sheet http://www.westerncape.gov.za/Text/2005/7/facts_about_immunisation.pdf (Retrieved, 25 April 2011).

Feemster, A. K., Spain, V. C., Eberhart, M., Pati, S. \& Watson, B. (2009). Identifying infants at increased risk for late initiation of immunization: Maternal and provider characteristics: Public health Report/JanuaryFebruary 2009/volume 124 .

Gyekye, A. B. \& Akinboade, O. A. (2001). The Determinants of Poverty in the Northern Province of South Africa: Implication for Policy. National Research Foundation Team Research Project,(Ref. Number 15/1/3/19/00370. Pretoria.

Kiely, L. J. \& Michael, D. K. (1994).Productive health of women; prenatal care, CDC's public health surveillance for women, infants and children.

Kyei, K. A. (1999). The mode of feeding that promotes higher survival among children. In: UAPS. The African Population in the $21^{\text {st }}$ century. Dakar: UAPS, 1, 193-212.

Menard, S. (1995). Applied Logistic Regression Analysis, Second edition. London, Sage University publications, 2002, Volume 106.

Peck, J. \& Alexander, K. (2012). Maternal, infants, and child health in rural areas http://www.srph.tamhsc.edu/centers/rhp2010/07Volume1MIC.htm. Retrieved, 4November, 2012.

Ruzicka, L., Wunsch, G. \& Kane, P. (1989). Differential Mortality: Methodological Issues and Biosocial Factors. Oxford: Claredon Press. 
Shung-King, M. (2010). HIV and health-immunization coverage of children, Children's institute University of Cape Town.

STATSSA. (2003). Yearly Statistical release. http:/www.statssa.gov.za Retrieved, 5 June 2010.

STATSSA. (2008). Yearly Statistical release. http:/www.statssa.gov.zawww.wikipedia.com.Retrieved, 20 September 2010.

STATSSA. (2013). 2011 Census. Preliminary Results. http:/www.statssa.gov.za Retrieved, 15 June 2013.

Tecke, B. \& Shorter, C. (1984). Determinants of Child Mortality: A study of squatter settlements in Jordan. Population and Development, Supplement to, 10, 257-280.

UNICEF South Africa. (2008). Child Survival and Development-mothers and child health. http://www.unicef.org/southafrica/survival_devlop_759.html(Retrieved, 5 May 2011)

WHO. (2011). Pneumonia factsheet $\mathrm{N}^{0} 331 \quad$ October 2011. http://www.who.int/medicacentre/factsheets/fs331/en/index.html.(Retrieved, 3 June 2011).

WHO. (2009). Factsheet $\mathrm{N}^{0} 330$. Diarrheal disease, Media centre. http://www. who.int/media centre/factsheets/fs330/en/index.html. (Retrieved, 5 May 2011).

http://www.dtreg.com/logistic.htm. (Retrieved, 27 August 2011).

http://www.thenews.com.pk/NewsDetai.aspx?ID=13046. (Retrieved, 22 March 2011). 